\title{
Microarray-based detection of extended virulence and antimicrobial resistance gene profiles in phylogroup B2 Escherichia coli of human, meat and animal origin
}

Lotte Jakobsen, ${ }^{1}$ Philippe Garneau, ${ }^{2}$ Azra Kurbasic, ${ }^{3} \ddagger$ Guillaume Bruant, ${ }^{2} \S$ Marc Stegger, ${ }^{1}$ Josée Harel, ${ }^{2}$ Klaus S. Jensen, ${ }^{1}$ Roland Brousseau, ${ }^{4} \dagger$ Anette M. Hammerum ${ }^{1}$ and Niels Frimodt-Møller ${ }^{1}$

Correspondence

Lotte Jakobsen

lja@ssi.dk
Received 4 May 2011 Accepted 25 May 2011

\author{
${ }^{1}$ Department for Microbiological Surveillance and Research, Statens Serum Institut, Artillerivej 5, \\ DK-2300 Copenhagen S, Denmark \\ ${ }^{2}$ Groupe de Recherche sur les Maladies Infectieuses du Porcine, Faculté de Médecine Vétérinaire \\ and Centre de Recherche en Infectiologie Porcine, Université du Montreal, 3200 Sicotte, \\ Saint-Hyacinthe, OC J2S 7C6, Canada \\ ${ }^{3}$ Biostatistical Department, Statens Serum Institut, Artillerivej 5, DK-2300 Copenhagen S, Denmark \\ ${ }^{4}$ Biotechnology Research Institute, National Research Council of Canada, 6100 Royalmount \\ Avenue, Montreal, QC H4P 2R2, Canada
}

\begin{abstract}
Extra-intestinal pathogenic Escherichia coli (ExPEC) causing urinary tract infections (UTIs) most often belong to phylogenetic group B2 and stem from the patient's own faecal flora. It has been hypothesized that the external reservoir for these uropathogenic $E$. coli in the human intestine may be meat and food-production animals. To investigate such a connection, this study analysed an E. coli phylogroup B2 strain collection $(n=161)$ of geographical and temporally matched isolates, published previously, from UTI patients $(n=52)$, community-dwelling humans $(n=36)$, imported $(n=5)$ and Danish $(n=13)$ broiler chicken meat, Danish broiler chickens $(n=17)$, imported $(n=3)$ and Danish $(n=27)$ pork, and healthy Danish pigs $(n=8)$. The isolates were subjected to microarray analysis for 315 virulence genes and variants and 82 antimicrobial resistance genes and variants. In total, 133 different virulence and antimicrobial resistance genes were detected in at least one UTI isolate. Between 66 and 87 of these genes were also detected in meat and animal isolates. Cluster analyses of virulence and resistance gene profiles, respectively, showed that UTI and community-dwelling human isolates most often grouped with meat and animal isolates, indicating genotypic similarity among such isolates. Furthermore, B2 isolates were detected from UTI patients and meat, with indistinguishable gene profiles. A considerable proportion of the animal and meat isolates belonged to the ExPEC pathotype. In conclusion, these findings suggest that B2 E. coli from meat and animal origin can be the source of most of the virulence and antimicrobial resistance genes detected in uropathogenic $E$. coli isolates and that there is a general resemblance of animal, meat and UTI E. coli based on extended gene profiling. These findings support the hypothesis of a zoonotic link between E. coli causing UTIs and E. coli from meat and animals.
\end{abstract}

tDr Brousseau passed away before the completion of the study.

‡Present address: Steno Diabetes Center A/S, Niels Steensens Vej 2, DK-2820 Gentofte, Denmark.

§Present address: Biotechnology Research Institute, National Research Council of Canada, 6100 Royalmount Avenue, Montreal, QC H4P 2R2, Canada.

Abbreviations: APEC, avian pathogenic Escherichia coli; DAEC, diffusely adherent E. coli; EAEC, enteroaggregative E. coli; EIEC, enteroinvasive E. coli; EHEC, haemorrhagic E. coli; EPEC, enteropathogenic E. coli; ETEC, enterotoxigenic E. coli; ExPEC, extra-intestinal pathogenic E. coli; LEE, locus of enterocyte effacement; MNEC, meningitis-associated E. coli; SEPEC, septicaemic E. coli; STEC, Shiga-toxin-producing E. coli; UPEC, uropathogenic E. coli; UTI, urinary tract infection.

Three supplementary tables are available with the online version of this paper. 


\section{INTRODUCTION}

Escherichia coli is a highly versatile species. It can be a commensal in the gut of both humans and animals, as well as a pathogen causing intestinal and extra-intestinal infections (Johnson \& Russo, 2002). The latter - caused by extraintestinal pathogenic E. coli (ExPEC), notably include bacteraemia, human neonatal meningitis, avian colibacillosis and urinary tract infections (UTIs) (Johnson \& Russo, 2002; Rodriguez-Siek et al., 2005). UTIs are one of the most common bacterial infections, caused mainly by $E$. coli belonging to phylogroups B2 and D (Foxman, 2003; Johnson et al., 2005a; Moreno et al., 2008; Takahashi et al., 2006).

ExPEC isolates seem to differ from commensal E. coli by carrying more virulence genes (Johnson \& Russo, 2002). Studies have shown a link between the degree of infection in a murine model and the number of virulence genes in the individual E. coli isolates (Denamur et al., 2000; Ewers et al., 2009; Johnson \& Kuskowski, 2000; Wiles et al., 2008). In addition to virulence genes, $E$. coli strains often also carry several antimicrobial resistance genes (Grape et al., 2005; Maynard et al., 2004; Oteo et al., 2009; Song et al., 2009). Antimicrobial resistance to $E$. coli is increasing worldwide (Gupta, 2003).

It was proposed recently that food and animals may be the source of ExPEC causing UTIs (Ramchandani et al., 2005). The purpose of this study was to investigate: (i) which specific virulence and resistance genes are carried by $E$. coli isolated from UTI patients, community-dwelling humans, meat and production animals; and (ii) to what extent E. coli from production animals and meat resemble $E$. coli from community-dwelling humans and UTI patients. Similar characteristics could suggest that animal and meat isolates are likely sources for uropathogenic $E$. coli. In addition, we wanted to explore the pathotypes of all isolates to appreciate the general virulence potential of isolates from different habitats. To do this, we genetically characterized 161 geographically and temporally matched phylogroup B2 isolates from the urine of UTI patients, faecal samples from community-dwelling humans, imported and Danish broiler chicken meat, faecal samples from Danish broiler chickens, imported and Danish pork, and Danish pig faecal samples using a microarray capable of detecting almost 400 virulence and resistance genes (Jakobsen et al., 2010c).

\section{METHODS}

E. coli B2 isolates. A total of 964 geographically and temporally matched E. coli isolates from broiler chickens $(n=138)$, Danish $(n=197)$ and imported $(n=86)$ broiler chicken meat, pigs $(n=145)$, Danish $(n=177)$ and imported $(n=10)$ pork, community-dwelling humans $(n=109)$ (all collected in Denmark in 2004 using stratified sampling schemes) and UTI patients $(n=102$, collected in one region of Denmark in 2005-2006) were collected previously and analysed for phylogroup (A, B1, B2 and D) (Jakobsen et al., 2010b, c). Faecal sampling of community-dwelling human isolates was approved by the Frederiksberg scientific ethical committee [(KF) 01-006/02]. The invited individuals were selected using an algorithm taking the age and gender distribution of the total Danish population, as well as the differential participation rates of various demographic groups, into account. For meat isolates, wholesale and retail outlets were chosen randomly in all regions of Denmark, and the meat samples were representative of the meat on sale for that year. For the foodproduction animal isolates, faecal samples were collected at slaughter houses (each sample represented one flock or herd), and the number of samples was proportional to the number of animals slaughtered each year in each individual slaughter house. Meat from the individual slaughter houses was distributed all over Denmark. Only one E. coli isolate was taken from each human individual, meat sample and food-production animal.

Of these 964 isolates, 161 belonged to phylogroup B2 and were targeted for this study. The B2 isolates were obtained from UTI patients $(n=52)$, community-dwelling humans $(n=36)$, imported $(n=5)$ and Danish $(n=13)$ broiler chicken meat, Danish broiler chickens $(n=17)$, imported $(n=3)$ and Danish $(n=27)$ pork and healthy Danish pigs $(n=8)$.

Microarray experiments. All microarray hybridizations were performed with an updated version of the previously described oligonucleotide microarray capable of detecting an exhaustive list of E. coli virulence genes and most of the antimicrobial resistance genes found in pathogenic Gram-negative bacteria (Bruant et al., 2006). With the additional probes (see Supplementary Tables S1 and S2, available in JMM Online), the updated version of the E. coli DNA microarray allowed the detection of $315 \mathrm{E}$. coli-specific virulence genes and 82 antimicrobial resistance genes, including most known variants. The updated microarray was validated by performing hybridizations with DNA from a collection of $E$. coli control strains representing all known pathotypes and by PCR (data not shown).

DNA extraction and labelling. Extraction of DNA was performed as described previously (Bruant et al., 2006) by bacterial cell lysis except that an increased starting culture volume ( $1 \mathrm{ml}$ instead of $200 \mu \mathrm{l})$ was used. DNA labelling was performed as described previously (Bruant et al., 2006) with the two following modifications: $10 \mu \mathrm{E}$. coli lysate was used as template instead of $15 \mu \mathrm{l}$ and the labelling reaction time was shorter, being stopped after $3 \mathrm{~h}$ instead of $3.5 \mathrm{~h}$.

Hybridizations and data acquisition. Hybridizations on E. coli virulence microarrays were performed as described previously (Bruant et al., 2006). After hybridization, arrays were scanned with a ScanArray Lite fluorescent microarray analysis system (Canberra-Packard Canada), and acquisition and quantification of fluorescent spot intensities were performed using ScanArray Express software, version 2.1 (Perkin-Elmer). For all microarray data, the local background was subtracted from the recorded spot intensities. The median value of each set of duplicate spotted oligonucleotides was then compared with the median value of the negative-control spots present on the array. Oligonucleotides with a signal-to-noise fluorescence ratio of $>3.0$ were considered positive (Bruant et al., 2006). Using the Delphi software (Borland Delphi Professional, version 7.0; Borland Software Corp.), we made a simple program for identifying isolates with identical microarray gene profiles. The information on microarray probes can be found in Supplementary Table S1 (targeting virulence genes as well as internal controls) and Supplementary Table S2 (targeting antimicrobial resistance and mobile element genes).

Pathotype assignment. Each strain of the study was assigned to a specific E. coli pathotype according to its virulence gene profile and based on previously described classifications (Bruant et al., 2006; Hamelin et al., 2007). Isolates were assigned to intestinal E. coli pathotypes based on the presence of specific virulence genes, such as locus of enterocyte effacement (LEE) genes and heat-stable, heat-labile or Shiga-like toxin-encoding genes (Bruant et al., 2006). E. coli isolates 
were classified as enterotoxigenic (ETEC) if they possessed heat-stable and/or heat-labile toxin-encoding genes as well as CFA, F4 and F18 fimbriae-encoding genes. E. coli isolates were considered as Shigatoxin-producing (STEC) if they possessed $s t x_{1}$ and/or $s t x_{2}$ genes, and if, in addition, they possessed LEE genes, they were considered as attaching and effacing STEC or enterohaemorrhagic E. coli (EHEC). E. coli isolates were classified as enteropathogenic (EPEC) if they possessed the LEE genes as well as the bundle-forming pili (BFP)encoding genes, and as atypical EPEC if they only possessed the LEE genes and lacked the BFP-encoding genes. E. coli isolates possessing the genes capU, shf and virK and aggregative adherence fimbriae-encoding genes were considered to be enteroaggregative (EAEC). E. coli isolates that possessed invasion-encoding genes were classified as enteroinvasive (EIEC) and E. coli isolates possessing the gene aidaI were considered as diffusely adherent (DAEC).

Whilst intestinal pathotypes are clearly defined, there is no established classification for ExPEC isolates. The criteria elaborated by Johnson (2003) were used to classify E. coli isolates as potential ExPEC. Isolates must possess two or more of the following virulence genes: pap ( $\mathrm{P}$ fimbriae), $s f a$ or $f o c$ (S/F1C fimbriae), afa or dra (Dr-binding adhesins), iutA (aerobactin receptor) and kpsMII (group II capsule synthesis) (Hamelin et al., 2007; Johnson, 2003). ExPEC strains branched into several subgroups such as uropathogenic E. coli (UPEC), meningitis-associated E. coli (MNEC), septicaemic E. coli (SEPEC) and avian pathogenic E. coli (APEC). Based on these classifications, E. coli isolates that possessed $\mathrm{P}$ pilus- and/or $\mathrm{S}$ fimbriae-encoding genes and iron acquisition or transport genes were classified as ExPEC subgroup UPEC. E. coli isolates possessing the invasion-encoding gene ibe $A$ and capsular-related genes such as $k p s M$, $n e u A$ and $n e u C$, as well as iron acquisition or transport genes, were classified as subgroup MNEC. E. coli isolates that possessed the toxinencoding genes $c d t$ and/or $c n f$, the traT gene encoding a complement resistance protein, the iss (increased serum survival) gene and the pap gene, as well as F17-encoding genes (and their variants), together with capsule K1 (neuA) or K2 (kpsmII) markers and iron uptake-related genes, were considered to be subgroup SEPEC. Although the set of virulence factors possessed by an APEC isolate is variable, APEC classification was based on a recent study, where an isolate was 'potentially APEC' when it possessed a combination of any four or more of the five following genes or gene groups: iss, tsh (temperaturesensitive haemagglutinin), $\mathrm{P}$ or $\mathrm{S}$ fimbriae-encoding genes, iron acquisition or transport genes, and kpsMII (Bonnet et al., 2009). It should be considered, however, that no true genotype of APEC has been generally agreed on and that isolates cannot be stated as truly APEC unless they have been proven to be infectious in vivo.

Finally, if isolates possessed none or a few virulence genes not attributed to any of the pathotypes described above, they were regarded as 'potentially non-pathogenic E. coli'.

Statistical analysis. The individual isolate was the unit of statistical analysis. Comparisons of the proportions of the individual pathotypes among isolate origins were analysed using Fisher's exact test (twotailed) with a significance level of $P \leqslant 0.05$ (GraphPad Prism 5; GraphPad Software). Comparisons of the number of genes per isolate among the eight origins were analysed using the Mann-Whitney test (GraphPad Prism 5).

In addition, we analysed how E. coli isolates clustered based on their virulence gene and antimicrobial resistance gene profiles, using PROC CLUSTER in SAS version 9.2 (SAS Institute). Only genes detected in at least one isolate were included in the analysis. In the cluster analyses, we used Ward's minimum variance clustering method and the DSQMATCH method (simple matching coefficient transformed to squared Euclidean distance) to measure distance. This coefficient takes $1-1$ and $0-0$ matching into account. The results were visualized in a dendrogram (PROC TREE in SAS version 9.2). When analysing the antimicrobial resistance gene profiles, isolates from all origins with no resistance genes were represented as one isolate in the analysis (designated 'mixed'). These isolates had identical sequences of zeros for all the genes. For this reason, the algorithm would group these isolates in one cluster anyway. However, including the 'mixed' category made the figure more readable.

\section{RESULTS}

\section{Frequency of virulence and antimicrobial resistance genes among isolates from different origins}

Overall, 169 virulence and 36 antimicrobial resistance genes among the 315 and 82 genes and variants investigated were detected at least once in one or more of the isolates. The total number of virulence genes per isolate ranged from 25 to 60 genes, irrespective of the isolate origin (Table 1). Although the median number of virulence genes per isolate was similar (37-47 genes) among the different origins, significantly more virulence genes per isolate were detected among UTI isolates compared with community-dwelling humans $(P=0.027)$, imported broiler chicken meat $(P=0.028)$, and broiler chicken isolates $(P=0.001)$, respectively (Table 1$)$. Significantly more virulence genes were also found in Danish pork isolates compared with community-dwelling human $(P=0.009)$, Danish broiler chicken meat $(P=0.005)$ and broiler chicken isolates $(P<0.001)$ (Table 1$)$. The total number of antimicrobial resistance genes ranged from 0 to 17 genes among isolates from all origins (Table 1). The median number of antimicrobial resistance genes per isolate was zero for most isolates, with the exception of Danish and imported pork and pig isolates, for which the median number of antimicrobial resistance genes per isolate was significantly higher compared with isolates from most other origins $(P \leqslant 0.05)$ (Table 1$)$. Among the different origins, a total of $39-100 \%$ of the isolates carried one or more antimicrobial resistance genes. The distribution of all virulence and antimicrobial resistance genes detected among E. coli isolates from all origins, as well as the frequency of each individual gene, are summarized in Supplementary Table S3, available in JMM Online.

A total of 133 virulence and antimicrobial resistance genes were detected at least once among the UTI isolates. In comparison, a total of 75-136 genes were detected once or more in isolates from the seven other origins. There was a considerable overlap between the array of genes detected in UTI isolates and genes detected in isolates from the other origins: community-dwelling humans (109 genes), imported (66 genes) and Danish (84 genes) broiler chicken meat, broiler chickens (66 genes), imported (72 genes) and Danish (87 genes) pork and pigs (82 genes) (Supplementary Table S1).

Some virulence genes were detected in isolates from all origins (Table 2). These 39 genes encoded many different functions, including adhesins, colicins and microcins, toxins, iron acquisition or transport systems, capsular 
Table 1. Median number and range of virulence and antimicrobial resistance genes and variants in $E$. coli $\mathrm{B} 2$ isolates from all origins

\begin{tabular}{|c|c|c|c|c|c|c|c|c|}
\hline & \multicolumn{8}{|c|}{ Median number and range of genes in isolates from: } \\
\hline & $\begin{array}{l}\text { UTI patients } \\
\quad(n=52)\end{array}$ & $\begin{array}{c}\text { Community- } \\
\text { dwelling } \\
\text { humans } \\
(n=36)\end{array}$ & $\begin{array}{l}\text { Imported broiler } \\
\text { chicken meat } \\
\qquad(n=5)\end{array}$ & $\begin{array}{l}\text { Danish broiler } \\
\text { chicken meat } \\
\quad(n=13)\end{array}$ & $\begin{array}{c}\text { Broiler } \\
\text { chickens } \\
(n=17)\end{array}$ & $\begin{array}{c}\text { Imported } \\
\text { pork } \\
(n=3)\end{array}$ & $\begin{array}{l}\text { Danish pork } \\
\qquad(n=27)\end{array}$ & $\begin{array}{c}\text { Pigs } \\
(n=8)\end{array}$ \\
\hline \multicolumn{9}{|l|}{ Resistance genes } \\
\hline Range $(n)$ & $0-15$ & $0-11$ & $0-6$ & $0-5$ & $0-3$ & $2-5$ & $0-17$ & $0-12$ \\
\hline \multicolumn{9}{|l|}{ Virulence genes } \\
\hline Median $(n)$ & 46 & 42 & 37 & 45 & 41 & 47 & 47 & 47 \\
\hline Range $(n)$ & $34-60$ & $32-51$ & $25-50$ & $37-48$ & $28-50$ & $29-48$ & $29-49$ & $29-55$ \\
\hline
\end{tabular}

and somatic antigens, and haemolysins and haemagglutinins. No antimicrobial resistance gene was found to be common to all isolate origins. Some virulence and antimicrobial resistance genes $(n=12)$ were detected among isolates from human sources and broiler chicken meat and/or broiler chickens only, and some virulence genes $(n=6)$ were detected only among isolates from humans and pigs and/or pork (Table 3 ). Some of the tested virulence and antimicrobial resistance genes were detected only in one reservoir (Table 4). The number of genes detected exclusively among isolates from one origin varied from 0 to 14 genes (Table 4 ).

Finally, a total of 39 isolates from all origins exhibited 16 indistinguishable virulence and antimicrobial resistance gene profiles (each containing two to four isolates). The profiles comprised 36-52 genes (data not shown).

\section{Pathotyping}

In general, the majority of isolates from a given origin belonged to ExPEC (and the ExPEC subtypes, such as

Table 2. Virulence genes $(n=39)$ detected among $E$. coli B2 isolates from all origins

\begin{tabular}{|c|c|}
\hline Function & Gene(s) \\
\hline Adhesins & $\operatorname{csg} A, \operatorname{csg} E$, fimA, fimH \\
\hline Colicins and microsins & cvaC \\
\hline Toxins & astA \\
\hline $\begin{array}{l}\text { Iron acquisition or } \\
\text { transport systems }\end{array}$ & $\begin{array}{l}\text { chuA, fepC, iroN, fyuA, } \\
\text { irp1, irp2, iucD, iutA, } \\
\text { sitA, sitD }\end{array}$ \\
\hline Capsular and somatic antigens & kpsMII, пеиА, пеиС \\
\hline Haemolysins and haemagglutinins & hlyE, hral, tsh, vat \\
\hline Various functions & $\begin{array}{l}\text { agn } 43, \text { fliC, ibeA, ibeB, } \\
\text { iss, malX, ompA, ompT, } \\
\text { traT, usp }\end{array}$ \\
\hline $\begin{array}{l}\text { Newly recognized or } \\
\text { putative E. coli virulence genes }\end{array}$ & $\begin{array}{l}y j a A, \text { tspE.c2, artJ, b1121, } \\
\text { mviM, mviN }\end{array}$ \\
\hline
\end{tabular}

UPEC, MNEC and APEC) except for imported broiler chicken meat, imported pork and broiler chicken isolates (Table 5). A single ExPEC isolate could be classified in more than one subgroup according to its gene set. The multiple classification of a single isolate is a result of the individual ExPEC subgroups not having a set of specific subgroup-identifying virulence genes (Hamelin et al., 2007). None of the isolates was classified as both an intestinal and an extra-intestinal pathotype.

\section{Cluster analyses of virulence and antimicrobial resistance gene profiles}

In total, 169 genes were included in the cluster analysis of virulence genes and variants, which resulted in ten clusters, each comprising three to 39 isolates (Fig. 1). UTI isolates clustered together with meat isolates in five

Table 3. Virulence genes detected among E. coli B2 isolates from all but a few origins

UTI, UTI patients; CDH, community-dwelling humans; DBCM, Danish broiler chicken meat; IBCM, imported broiler chicken meat; BC, broiler chickens; IP, imported pork; DP, Danish pork; P, pigs.

\begin{tabular}{|c|c|c|}
\hline Isolate origin & Function & Gene(s) \\
\hline \multirow[t]{2}{*}{$\begin{array}{l}\text { UTI, CDH and } \\
\text { DBCM and/or } \\
\text { IBCM and/or BC }\end{array}$} & Adhesins & $\begin{array}{l}f 165(1) A, \\
\text { papA(11), } \\
\text { papGII }\end{array}$ \\
\hline & $\begin{array}{l}\text { Colicins and } \\
\text { microcins } \\
\text { Antimicrobial } \\
\text { resistance }\end{array}$ & $\begin{array}{l}c e i, \text { mccB, } \\
\text { mcjA } \\
\text { sull, dhfrI, } \\
\text { dhfrVIII, int1, } \\
\text { int2, qac }\end{array}$ \\
\hline \multirow[t]{3}{*}{$\begin{array}{l}\text { UTI, CDH and IP } \\
\text { and/or DP and/or P }\end{array}$} & Adhesins & $\begin{array}{l}\text { focG, papA(12), } \\
\text { papA(13) }\end{array}$ \\
\hline & Toxins & cnfl, st $2 t B$ \\
\hline & $\begin{array}{l}\text { Haemolysins and } \\
\text { haemagglutinins }\end{array}$ & hlyA \\
\hline
\end{tabular}


Table 4. Virulence and antimicrobial resistance genes detected exclusively among $E$. coli $\mathrm{B} 2$ isolates from a single origin

The number of isolates is given in parentheses.

\begin{tabular}{|c|c|c|c|c|c|c|c|c|}
\hline Function & $\begin{array}{l}\text { UTI patients } \\
\qquad(n=52)\end{array}$ & $\begin{array}{l}\text { Community- } \\
\text { dwelling } \\
\text { humans } \\
(n=36)\end{array}$ & $\begin{array}{c}\text { Imported } \\
\text { broiler } \\
\text { chicken meat } \\
(n=5)\end{array}$ & $\begin{array}{l}\text { Danish broiler } \\
\text { chicken meat } \\
\text { t } \quad(n=13)\end{array}$ & $\begin{array}{c}\text { Broiler } \\
\text { chickens } \\
(n=17)\end{array}$ & $\begin{array}{l}\text { Imported pork } \\
\qquad(n=3)\end{array}$ & $\begin{array}{l}\text { Danish pork } \\
\quad(n=27)\end{array}$ & Pigs $(n=8)$ \\
\hline Resistance & $\begin{array}{l}\text { catI }(2), \text { mphA (1), } \\
\text { blaOXA-1 (1), } \\
\text { blaPER2 }(1)\end{array}$ & & & & $o q x A(1)$ & $b l a \_R O B I(1)$ & $\begin{array}{c}\text { bla_OXA9 (1), } \\
\text { bla_CTX_M12 } \\
(1), \text { oqXB (2), } \\
\text { dhfrXIII (1) }\end{array}$ & $d h f r V(1)$ \\
\hline Adhesins & $\begin{array}{l}a f a E 3(1), \\
d r b E(121)(1), \\
\operatorname{csn} A(1), \operatorname{sfaA}(2), \\
\operatorname{papA}(8)(2), \\
\operatorname{papA}(9)(1), \\
\operatorname{papA}(15)(1)\end{array}$ & $\operatorname{csd} A(1)$ & & & $\begin{array}{c}\cot A(1) \\
\operatorname{csf} A(1)\end{array}$ & & & \\
\hline $\begin{array}{l}\text { Colicins and } \\
\text { microsins }\end{array}$ & $c d a(1)$ & & & can (1) & $\operatorname{mclC}(2)$ & & & \\
\hline Toxins & & & & tox $B(1)$ & & & & \\
\hline $\begin{array}{l}\text { Capsular } \\
\text { and somatic } \\
\text { antigens }\end{array}$ & $\begin{array}{l}k p s M-I I I(2) \\
w z y(O 117)\end{array}$ & $\begin{array}{c}w z y(\mathrm{O} 45 \mathrm{KI}) \\
w z y(\mathrm{O}) \\
\end{array}$ & & & & & $\begin{array}{l}w z y(O 177) \\
(1)\end{array}$ & \\
\hline LEE genes & & eae(alpha) (1) & & & $\begin{array}{l}\text { eae(beta) (1), } \\
\text { espA-I (1), } \\
\text { espB-3 (1), } \\
\text { tir-I (1), } \\
\text { map-I (1) }\end{array}$ & & eae(iota) (1) & eae(zeta) (1) \\
\hline $\begin{array}{l}\text { Non-LEE } \\
\text { elements }\end{array}$ & & $\begin{array}{c}e i b G(1), p a a(1) \\
p a a(E T E C)(1)\end{array}$ & & & $\begin{array}{l}\text { nleA }(E H E C) \\
(1), \\
\text { nleG(O157) } \\
(1)\end{array}$ & & nleC (1) & nleA(EPEC) (1) \\
\hline $\begin{array}{l}\text { Various } \\
\text { functions }\end{array}$ & & $\begin{array}{l}e i b C(1), \text { flmA54 } \\
\text { (1) }\end{array}$ & & & & & $\begin{array}{l}\operatorname{etpD}(1) \\
\operatorname{katP}(1)\end{array}$ & $\operatorname{sep} A(1)$ \\
\hline
\end{tabular}

of the ten clusters (clusters 3, 5, 8, 9 and 10). These five clusters comprised $75 \%$ of the B2 strains in the study (121/161 strains). In two of these clusters, UTI isolates also grouped with animals besides meat isolates (clusters 8 and 10). UTI isolates were present in only one other cluster (cluster 4) besides the above-mentioned five clusters (Fig. 1). Clusters 6 and 7 comprised isolates from community-dwelling humans, meat and animals but no UTI isolates.

A total of 36 genes were included in the cluster analysis of antimicrobial resistance gene profiles (Fig. 2). Seven clusters were identified comprising three to 109 isolates each. UTI isolates were present in all clusters, and were grouped together with isolates from meat (clusters 1-3 and 5-7) and production animals (clusters 3-7) (Fig. 2). Cluster 7, which contained 109 isolates including ten UTI isolates, was characterized mainly by a lack of antimicrobial resistance genes, as 76 isolates from all origins but imported pork were negative for all investigated resistance genes (designated 'mixed' in Fig. 2).

\section{DISCUSSION}

In the present study, we used an E. coli DNA microarray to analyse and compare the virulence and antimicrobial resistance gene profiles of phylogenetic group B2 E. coli isolates from UTI patients, community-dwelling humans, broiler chicken meat, broiler chickens, pork and pigs. To our knowledge, this study provides the most extensive characterization to date of temporally and geographically matched phylogroup B2 E. coli from multiple sources, including food animals, meat products and healthy and diseased humans.

Most interestingly, among the 133 different genes detected in UTI isolates, only a few $(n=14)$ were detected exclusively in UTI isolates. Whilst some of these 14 genes were associated with the ExPEC pathotype, others were not associated with any type. It is speculation whether these genes are linked to ExPEC. UTI isolates shared 66-87 genes with isolates from Danish and imported broiler chicken meat, broiler chicken, Danish and imported pork, and pigs, 
Table 5. Pathotypes of $E$. coli B2 isolates from UTI patients, community-dwelling humans, meat and food animals

Results are given as percentages.

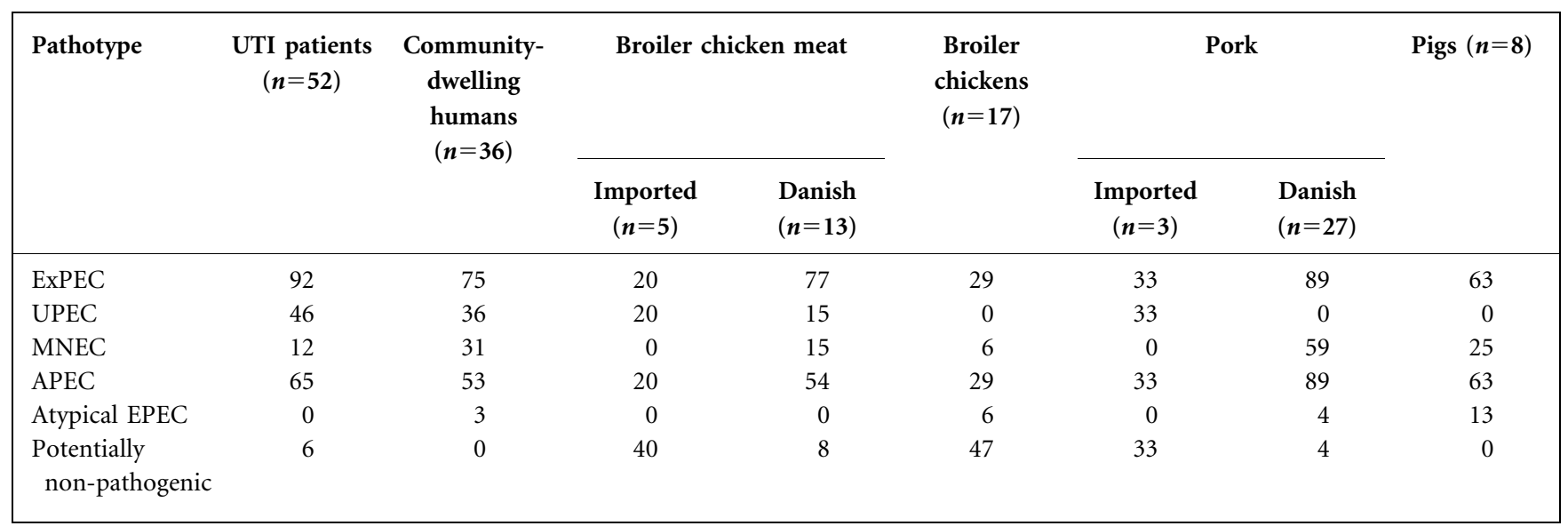

suggesting that meat and animals can indeed be sources of virulence and resistance genes for UTI isolates. Moreover, 45 virulence genes were detected among isolates from all eight origins. Many of the genes are associated not only with UTIs but also with other extra-intestinal diseases, and included genes such as the iron acquisition genes iutA and $\operatorname{iroN}$ (associated with UTIs), blood-brain barrier invasion protein ibeA (meningitis), serum-resistance iss (UTIs, meningitis, avian disease), biofilm-formation agn43 (UTIs, avian disease), pathogenicity island marker malX (extraintestinal disease) and $\mathrm{K} 1$ capsule-encoding neuC (neonatal meningitis) (Ewers et al., 2007; Huang et al., 1999; Johnson, 1991; Johnson et al., 2005c; Restieri et al., 2007; Rodriguez-Siek et al., 2005; Russo et al., 2002; Vann et al., 2004). These findings corroborate the hypothesis that production animals and meat are reservoirs of $E$. coli carrying ExPEC-specific virulence genes of importance for UTIs and other extra-intestinal diseases. The fact that so many genes are shared among isolates from different origins indicates that E. coli may not be host specific but possess the ability to adapt to many environments, including the human host, and possibly cause infection.

The $\mathrm{P}$ fimbriae genes such as $p a p A$ encoding the Pap fimbrial major subunit and papGII encoding Pap adhesion, which were detected in isolates from UTI patients, community-dwelling humans, Danish and/or imported broiler chicken meat, and broiler chicken isolates but were absent in pork and pig isolates, are associated with pyelonephritis in humans and have also been detected in MNEC and APEC (Ewers et al., 2007; Johnson, 1991). The four virulence genes detected in E. coli from humans and pork and/or pigs only but not in broiler chicken meat or broiler chickens were UPEC-associated adhesion-encoding genes focG, papA(12), papA(13) and the $\alpha$-haemolysin toxin-encoding gene hlyA (Johnson, 1991). This suggests that specific ExPEC-related genes may come from different sources. Finally, 14 genes (such as the archetypal UPECassociated $s f a A$ and $a f a$ genes) were detected exclusively in
UTI isolates, suggesting either the existence of other gene reservoirs not investigated in this study or the low occurrence of these genes in the veterinary isolates, or both.

Interestingly, although faecal isolates are considered to be commensals and meat isolates are usually thought to originate from faecal contamination, we found that E. coli isolates from healthy production animals and meat carried up to 55 virulence genes, which is almost as many as the UTI isolates (up to 60 virulence genes). Furthermore, a considerable proportion of the meat and animal E. coli isolates were assigned to the ExPEC pathotype (29-89\%) including UPEC and MNEC subgroups (6-59\%). This may signify a potential impact of such strains in and beyond the urinary tract. E. coli B2 isolates, regardless of the origin of the isolate, possess large numbers of virulence genes and should be regarded a potential threat to public health in regard to UTIs and possibly other extra-intestinal diseases.

The cluster analysis showed that UTI isolates grouped consistently with meat and/or animal isolates with respect to their antimicrobial resistance gene profiles and in seven (out of ten) clusters with respect to their virulence gene profiles. This provides proof of resemblance - and possibly a link - between E. coli from production animals/meat and UTI E. coli. This link was substantiated by the finding of isolates from these different origins sharing identical virulence and antimicrobial resistance gene profiles. This was an unexpected finding given the extensive number of genes in this gene profiling and the general flexibility of the E. coli gene pool.

Investigations of transmission (such as typing) were unfortunately not possible within the scope of the study. However, given the observation above, transfer of bacterial isolates from one habitat to another may be possible. It may also be possible that genes - and not just isolates - are exchanged between $E$. coli from different habitats through horizontal transfer; for example, the $c v a C$ gene, which is a marker for conjugative ColV plasmids known to enhance 


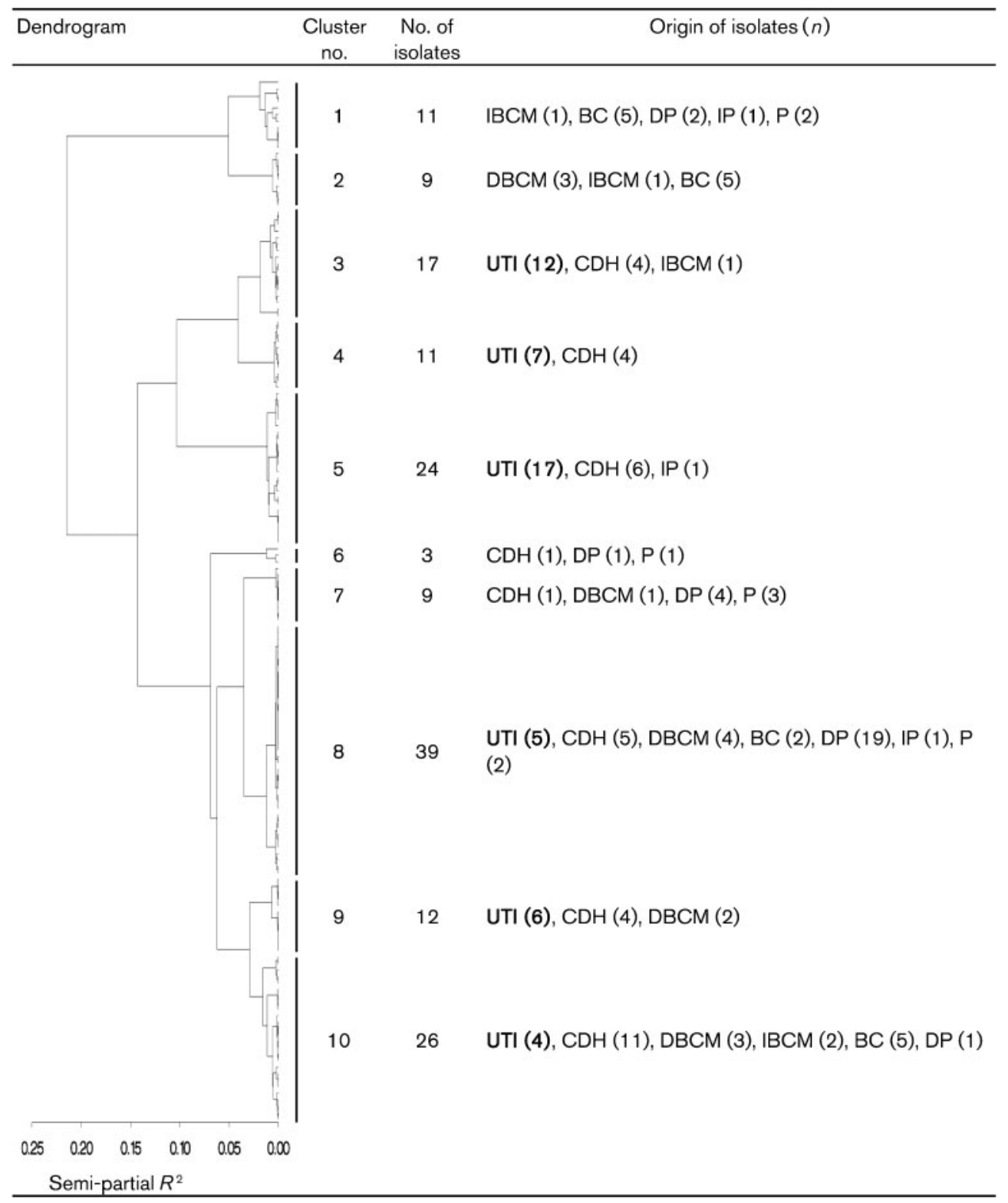

Fig. 1. Clustering of 161 E. coli B2 isolates from UTI patients (UTI), community-dwelling humans (CDH), imported broiler chicken meat (IBCM), Danish broiler chicken meat (DBCM), broiler chickens (BC), imported pork (IP), Danish pork (DP) and pigs $(P)$ based on the presence or absence of 169 virulence genes and variants. UTI isolates are highlighted in bold.

virulence through carriage of virulence genes, was found in several isolates from different origins. Likewise, integronencoding genes, which reside mostly on transposons and conjugative plasmids, were detected among isolates from all isolate origins (Depardieu et al., 2007; Fernandez-Beros et al., 1990; Johnson, 1991).

In our study, antimicrobial resistance genes encoding resistance to sulfonamide and trimethoprim were detected among isolates from pigs, pork, community-dwelling humans and UTI patients (but not broiler chickens or broiler chicken meat). Sulfonamide and trimethoprim are commonly used for treatment of UTIs in Denmark (Kerrn et al., 2002). The antimicrobial resistance in pig isolates was possibly a consequence of the relatively high use of antibiotics in pigs compared with low use in poultry production in Denmark. In 2004, the sulfonamide/ trimethoprim consumption in pigs equalled 7054 defined animal daily doses as opposed to the sulfonamide consumption in broiler chickens, which equalled 86 animal daily doses (DANMAP, 2005). The sulfonamide and trimethoprim resistance genes were possibly co-localized on mobile elements such as integrons, which were detected in isolates from these origins. 


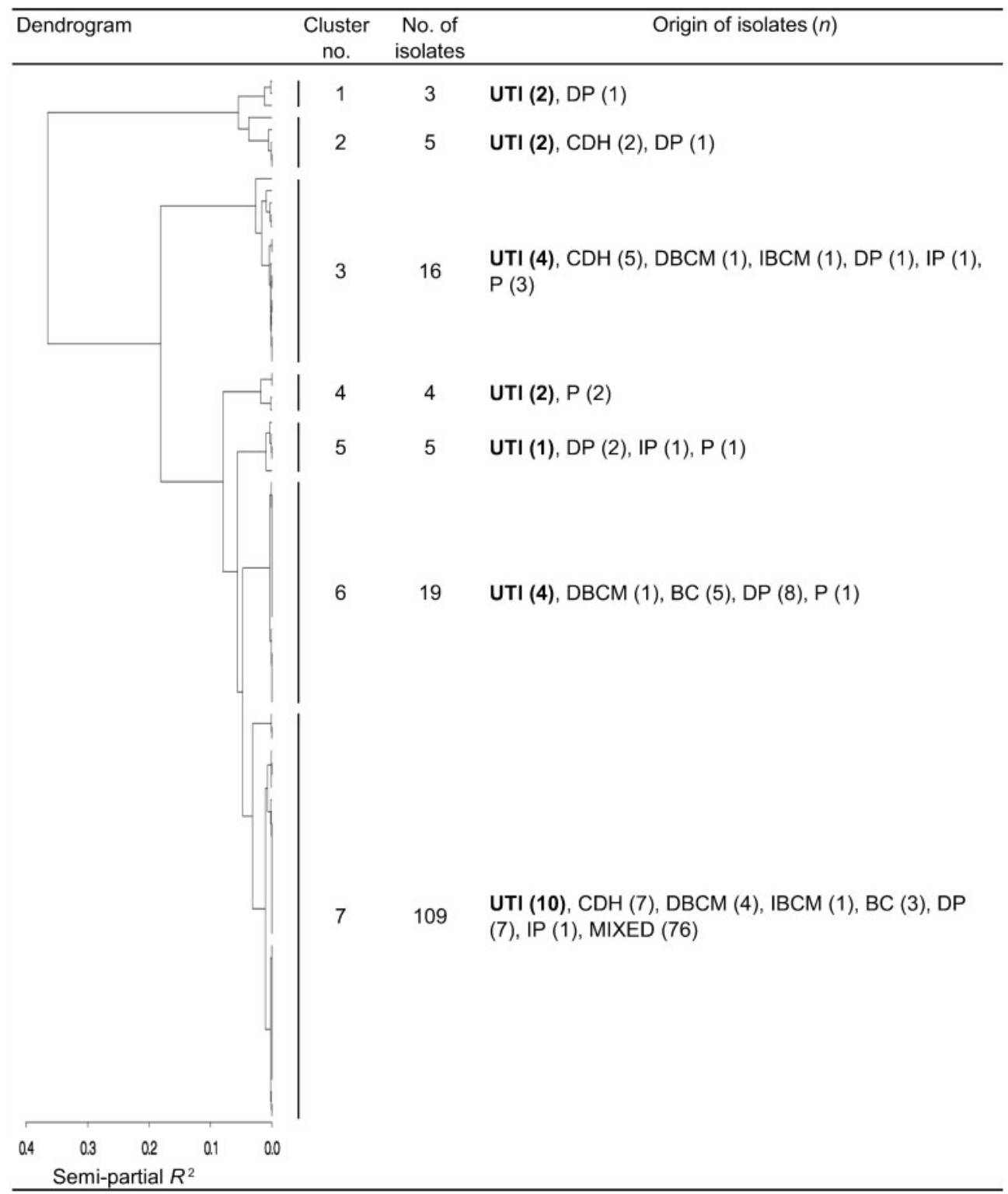

Fig. 2. Clustering of 161 E. coli B2 isolates from UTI patients (UTI), community-dwelling humans (CDH), imported broiler chicken meat (IBCM), Danish broiler chicken meat (DBCM), broiler chickens (BC), imported pork (IP), Danish pork (DP) and pigs (P) based on the presence or absence of 36 antimicrobial resistance genes and variants. 'Mixed' represents a group of isolates negative for any resistance gene from patients with UTIs $(n=27)$, community-dwelling humans $(n=22)$, Danish $(n=7)$ and imported chicken broiler meat $(n=3)$, broiler chickens (9), Danish pork $(n=7)$ and pigs $(n=1)$. UTI isolates are highlighted in bold.

Our results allow a fundamental step forward in the understanding of the full virulence potential and, to a lesser extent, of the antimicrobial resistance potential of UTI isolates as well as commensal animal and food isolates. UTI, animal and meat $E$. coli isolates have been investigated previously for their virulence genes but never to this extent, and only a few isolates were investigated simultaneously for antimicrobial resistance genes (Bonnet et al., 2009; Ewers et al., 2007, 2009; Hamelin et al., 2006, 2007; Hannah et al., 2009; Jakobsen et al., 2008; Johnson et al., 2005b, 2009; Maynard et al., 2004; Moulin-Schouleur et al., 2007; Ramchandani et al., 2005).
The extensive gene profiling, epidemiologically sampled isolates, analysis of B2 isolates only and the many isolate origins investigated here make up the strength of this study and provide radical difference from previous studies. Interestingly, despite this extensive gene profiling, similarities between isolates from UTI, animal and meat $E$. coli was clearly apparent. One limitation in our study was the limited numbers of B2 isolates from broiler chicken meat, broiler chickens, imported pork and pigs. Furthermore, there may be other unknown virulence genes of importance for UTIs that were not included in the array. 
Finally, of the 397 genes, three probes $[\operatorname{sop} A, \operatorname{tet}(D)$ and tnpM] on the microarray were in some cases prone to high background noise and may benefit from optimization in future studies.

In conclusion, cluster analyses of virulence and resistance gene profiles indicated a genotypic similarity between UTI and community-dwelling human isolates and meat and animal isolates. Furthermore, a considerable proportion of the animal and meat isolates belonged to an ExPEC pathotype, indicating their importance for human health. Finally, we detected B2 isolates from UTI patients and meat with indistinguishable gene profiles. This shows that B2 E. coli from meat and animal origin can be the source of most of the virulence and antimicrobial resistance genes detected in UPEC isolates. Thus, our findings support the hypothesis of a zoonotic link between UPEC and E. coli from animals and meat (Jakobsen et al., 2010a; Ramchandani et al., 2005; Vincent et al., 2010).

\section{ACKNOWLEDGEMENTS}

Christine Maynard, Katia Hamelin and Alberto Mazza, from the Biotechnology Research Institute (Quebec, Canada), are greatly acknowledged for their helpful advice on microarray data analyses. The authors would like to dedicate this study to the memory of Dr Roland Brousseau. This study would not have been possible without his invaluable contribution. This work is part of the Danish Integrated Antimicrobial Resistance Monitoring and Research Programme (DANMAP) and the Marie Curie program Training Risk-assessment in Non-human Antibiotic Usage (TRAINAU). The study is supported by the Danish Research Council (grant no. 210105-001), the Scandinavian Society for Antimicrobial Chemotherapy and in part by the Natural Sciences and Engineering Research Council of Canada (RGPIN-25120). The authors have no conflict of interest regarding this study.

\section{REFERENCES}

Bonnet, C., Diarrassouba, F., Brousseau, R., Masson, L., Topp, E. \& Diarra, M. S. (2009). Pathotype and antibiotic resistance gene distributions of Escherichia coli isolates from broiler chickens raised on antimicrobial-supplemented diets. Appl Environ Microbiol 75, 6955-6962.

Bruant, G., Maynard, C., Bekal, S., Gaucher, I., Masson, L., Brousseau, R. \& Harel, J. (2006). Development and validation of an oligonucleotide microarray for detection of multiple virulence and antimicrobial resistance genes in Escherichia coli. Appl Environ Microbiol 72, 3780-3784.

DANMAP (2005). DANMAP 2004. Use of antimicrobial agents and occurrence of antimicrobial resistance in bacteria from food animals, foods and humans in Denmark. http://www.danmap.org

Denamur, E., Elion, J. \& Picard, B. (2000). Clonal origin, virulence factors, and virulence [authors' reply]. Infect Immun 68, 424-425.

Depardieu, F., Podglajen, I., Leclercq, R., Collatz, E. \& Courvalin, P. (2007). Modes and modulations of antibiotic resistance gene expression. Clin Microbiol Rev 20, 79-114.

Ewers, C., Li, G., Wilking, H., Kiessling, S., Alt, K., Antáo, E. M., Laturnus, C., Diehl, I., Glodde, S. \& other authors (2007). Avian pathogenic, uropathogenic, and newborn meningitis-causing
Escherichia coli: how closely related are they? Int J Med Microbiol 297, 163-176.

Ewers, C., Antão, E. M., Diehl, I., Philipp, H. C. \& Wieler, L. H. (2009). Intestine and environment of the chicken as reservoirs for extraintestinal pathogenic Escherichia coli strains with zoonotic potential. Appl Environ Microbiol 75, 184-192.

Fernandez-Beros, M. E., Kissel, V., Lior, H. \& Cabello, F. C. (1990). Virulence-related genes in ColV plasmids of Escherichia coli isolated from human blood and intestines. J Clin Microbiol 28, 742-746.

Foxman, B. (2003). Epidemiology of urinary tract infections: incidence, morbidity, and economic costs. Dis Mon 49, 53-70.

Grape, M., Farra, A., Kronvall, G. \& Sundström, L. (2005). Integrons and gene cassettes in clinical isolates of co-trimoxazole-resistant Gram-negative bacteria. Clin Microbiol Infect 11, 185-192.

Gupta, K. (2003). Emerging antibiotic resistance in urinary tract pathogens. Infect Dis Clin North Am 17, 243-259.

Hamelin, K., Bruant, G., El-Shaarawi, A., Hill, S., Edge, T. A., Bekal, S., Fairbrother, J. M., Harel, J., Maynard, C. \& other authors (2006). A virulence and antimicrobial resistance DNA microarray detects a high frequency of virulence genes in Escherichia coli isolates from Great Lakes recreational waters. Appl Environ Microbiol 72, 4200-4206.

Hamelin, K., Bruant, G., El-Shaarawi, A., Hill, S., Edge, T. A., Fairbrother, J., Harel, J., Maynard, C., Masson, L. \& Brousseau, R. (2007). Occurrence of virulence and antimicrobial resistance genes in Escherichia coli isolates from different aquatic ecosystems within the St. Clair River and Detroit River areas. Appl Environ Microbiol 73, 477-484.

Hannah, E. L., Johnson, J. R., Angulo, F., Haddadin, B., Williamson, J. \& Samore, M. H. (2009). Molecular analysis of antimicrobialsusceptible and -resistant Escherichia coli from retail meats and human stool and clinical specimens in a rural community setting. Foodborne Pathog Dis 6, 285-295.

Huang, S.-H., Chen, Y.-H., Fu, Q., Stins, M., Wang, Y., Wass, C. \& Kim, K. S. (1999). Identification and characterization of an Escherichia coli invasion gene locus, ibeB, required for penetration of brain microvascular endothelial cells. Infect Immun 67, 2103-2109.

Jakobsen, L., Sandvang, D., Hansen, L. H., Bagger-Skjøt, L., Westh, H., Jørgensen, C., Hansen, D. S., Pedersen, B. M., Monnet, D. L. \& other authors (2008). Characterisation, dissemination and persistence of gentamicin resistant Escherichia coli from a Danish university hospital to the waste water environment. Environ Int 34, 108-115.

Jakobsen, L., Hammerum, A. M. \& Frimodt-Møller, N. (2010a). Virulence of Escherichia coli B2 isolates from meat and animals in a murine model of ascending urinary tract infection (UTI): evidence that UTI is a zoonosis. J Clin Microbiol 48, 2978-2980.

Jakobsen, L., Spangholm, D. J., Pedersen, K., Jensen, L. B., Emborg, H. D., Agersø, Y., Aarestrup, F. M., Hammerum, A. M. \& FrimodtMøller, N. (2010b). Broiler chickens, broiler chicken meat, pigs and pork as sources of ExPEC related virulence genes and resistance in Escherichia coli isolates from community-dwelling humans and UTI patients. Int J Food Microbiol 142, 264-272.

Jakobsen, L., Kurbasic, A., Skjøt-Rasmussen, L., Ejrnaes, K., Porsbo, L. J., Pedersen, K., Jensen, L. B., Emborg, H.-D., Agersø, Y. \& other authors (2010c). Escherichia coli isolates from broiler chicken meat, broiler chickens, pork, and pigs share phylogroups and antimicrobial resistance with community-dwelling humans and patients with urinary tract infection. Foodborne Pathog Dis 7, 537-547.

Johnson, J. R. (1991). Virulence factors in Escherichia coli urinary tract infection. Clin Microbiol Rev 4, 80-128.

Johnson, J. R. (2003). Microbial virulence determinants and the pathogenesis of urinary tract infection. Infect Dis Clin North Am 17, 261-278, viii. 
Johnson, J. R. \& Kuskowski, M. (2000). Clonal origin, virulence factors, and virulence [letter to the Editor]. Infect Immun 68, 424-425.

Johnson, J. R. \& Russo, T. A. (2002). Extraintestinal pathogenic Escherichia coli: "The other bad E. coli". J Lab Clin Med 139, 155-162.

Johnson, J. R., Kuskowski, M. A., Gajewski, A., Soto, S., Horcajada, J. P., Jimenez de Anta, M. T. \& Vila, J. (2005a). Extended virulence genotypes and phylogenetic background of Escherichia coli isolates from patients with cystitis, pyelonephritis, or prostatitis. J Infect Dis 191, 46-50.

Johnson, J. R., Kuskowski, M. A., Smith, K., O’Bryan, T. T. \& Tatini, S. (2005b). Antimicrobial-resistant and extraintestinal pathogenic Escherichia coli in retail foods. J Infect Dis 191, 1040-1049.

Johnson, J. R., Owens, K., Gajewski, A. \& Kuskowski, M. A. (2005c). Bacterial characteristics in relation to clinical source of Escherichia coli isolates from women with acute cystitis or pyelonephritis and uninfected women. J Clin Microbiol 43, 6064-6072.

Johnson, J. R., McCabe, J. S., White, D. G., Johnston, B., Kuskowski, M. A. \& McDermott, P. (2009). Molecular analysis of Escherichia coli from retail meats (2002-2004) from the United States national antimicrobial resistance monitoring system. Clin Infect Dis 49, 195-201.

Kerrn, M. B., Klemmensen, T., Frimodt-Møller, N. \& Espersen, F. (2002). Susceptibility of Danish Escherichia coli strains isolated from urinary tract infections and bacteraemia, and distribution of sul genes conferring sulphonamide resistance. J Antimicrob Chemother 50, 513-516.

Maynard, C., Bekal, S., Sanschagrin, F., Levesque, R. C., Brousseau, R., Masson, L., Larivière, S. \& Harel, J. (2004). Heterogeneity among virulence and antimicrobial resistance gene profiles of extraintestinal Escherichia coli isolates of animal and human origin. J Clin Microbiol 42, 5444-5452.

Moreno, E., Andreu, A., Pigrau, C., Kuskowski, M. A., Johnson, J. R. \& Prats, G. (2008). Relationship between Escherichia coli strains causing acute cystitis in women and the fecal E. coli population of the host. J Clin Microbiol 46, 2529-2534.

Moulin-Schouleur, M., Répérant, M., Laurent, S., Brée, A., MignonGrasteau, S., Germon, P., Rasschaert, D. \& Schouler, C. (2007). Extraintestinal pathogenic Escherichia coli strains of avian and human origin: link between phylogenetic relationships and common virulence patterns. J Clin Microbiol 45, 3366-3376.
Oteo, J., Diestra, K., Juan, C., Bautista, V., Novais, A., Pérez-Vázquez, M., Moyá, B., Miró, E., Coque, T. M. \& other authors (2009). Extendedspectrum $\beta$-lactamase-producing Escherichia coli in Spain belong to a large variety of multilocus sequence typing types, including ST10 complex/A, ST23 complex/A and ST131/B2. Int J Antimicrob Agents 34, 173-176.

Ramchandani, M., Manges, A. R., DebRoy, C., Smith, S. P., Johnson, J. R. \& Riley, L. W. (2005). Possible animal origin of human-associated, multidrug-resistant, uropathogenic Escherichia coli. Clin Infect Dis 40, 251-257.

Restieri, C., Garriss, G., Locas, M. C. \& Dozois, C. M. (2007). Autotransporter-encoding sequences are phylogenetically distributed among Escherichia coli clinical isolates and reference strains. Appl Environ Microbiol 73, 1553-1562.

Rodriguez-Siek, K. E., Giddings, C. W., Doetkott, C., Johnson, T. J., Fakhr, M. K. \& Nolan, L. K. (2005). Comparison of Escherichia coli isolates implicated in human urinary tract infection and avian colibacillosis. Microbiology 151, 2097-2110.

Russo, T. A., McFadden, C. D., Carlino-MacDonald, U. B., Beanan, J. M., Barnard, T. J. \& Johnson, J. R. (2002). IroN functions as a siderophore receptor and is a urovirulence factor in an extraintestinal pathogenic isolate of Escherichia coli. Infect Immun 70, 7156-7160.

Song, S., Lee, E. Y., Koh, E.-M., Ha, H. S., Jeong, H. J., Bae, I. K. \& Jeong, S. H. (2009). Antibiotic resistance mechanisms of Escherichia coli isolates from urinary specimens. Korean J Lab Med 29, 17-24.

Takahashi, A., Kanamaru, S., Kurazono, H., Kunishima, Y., Tsukamoto, T., Ogawa, O. \& Yamamoto, S. (2006). Escherichia coli isolates associated with uncomplicated and complicated cystitis and asymptomatic bacteriuria possess similar phylogenies, virulence genes, and O-serogroup profiles. J Clin Microbiol 44, 4589-4592.

Vann, W. F., Daines, D. A., Murkin, A. S., Tanner, M. E., Chaffin, D. O., Rubens, C. E., Vionnet, J. \& Silver, R. P. (2004). The NeuC protein of Escherichia coli $\mathrm{K} 1$ is a UDP $N$-acetylglucosamine 2-epimerase. J Bacteriol 186, 706-712.

Vincent, C., Boerlin, P., Daignault, D., Dozois, C. M., Dutil, L., Galanakis, C., Reid-Smith, R. J., Tellier, P. P., Tellis, P. A. \& other authors (2010). Food reservoir for Escherichia coli causing urinary tract infections. Emerg Infect Dis 16, 88-95.

Wiles, T. J., Kulesus, R. R. \& Mulvey, M. A. (2008). Origins and virulence mechanisms of uropathogenic Escherichia coli. Exp Mol Pathol 85, 11-19. 